\title{
Rescuing the Environment: Turning (Micro)plastics into Energy Through Gasification
}

\author{
Ana Ramos ${ }^{1}$, Abel Rouboa ${ }^{2}$ \\ ${ }_{1}^{1}$ NEGI - Institute of Science and Innovation in Mechanical and Industrial Engineering, Rua Dr. \\ Roberto Frias, 4200-465 Porto, Portugal (aramos@inegi.up.pt) ORCID 0000-0003-2185-1341 \\ ${ }^{2}$ INEGI - Institute of Science and Innovation in Mechanical and Industrial Engineering, Rua Dr. \\ Roberto Frias, 4200-465 Porto, Portugal; CITAB - University of Trás-os-Montes and Alto Douro, \\ Vila Real, Portugal (rouboa@utad.pt) ORCID 0000-0003-2652-8789
}

\begin{abstract}
Plastics are a common residue of our activities and, when incorrectly disposed, high quantities of this type of products end up in the environment, namely through landfilling and dumping into the aquatic compartments. Therefore, water streams and basins are contaminated threatening wildlife, which ultimately can entail human toxicity by means of the food-chain effect. One of the major concerns relies on microplastics which, due to its size and nature, constitute a more difficult to handle residue.

This paper presents an endeavour to control, reduce or even mitigate the presence of plastic debris in the environment, with the benefit of converting them into energy or other valuable commodities for the actual society. Gasification can be seen as one of the most effective techniques for this purpose, featuring a more environmental friendly scheme for treating this kind of residues, avoiding their overspread throughout Nature, as well as complying with environmental policies.
\end{abstract}

Author Keywords. Sustainability, Microplastics, Gasification

Type: Research Article

6 Open Access Peer Reviewed cC) CC BY

\section{Introduction}

The economic and social development seen in the last decades are thoroughly linked to the common use of products and technologies that enable easier ways of living, learning and working. Plastic and general synthetic goods are between the major humankind allies, being present in packaging, hygiene products, clothes, household appliances, and also as components of technological equipment like laptops, cell phones or any other current gadgets. Depending on the final purpose different plastics are used, which increments their contribution to the diversity and quantity of waste generated worldwide, hence complicating its management and safe disposal.

The plastics industry has shown a progressive development for more than 50 years, and is part of the top 5 most innovative sectors in the EU, reaching a production of 300million tonnes in 2015 (PlasticsEurope 2016; Eerkes-Medrano, Thompson, and Aldridge 2015). That year, the total plastic demand in Europe was 49 million tonnes, six countries concentrating $70 \%$ of the total demand, as shown in Figure 1. The remaining 30\% represented plastic necessities for 24 other countries. In developed countries, a high percentage of plastic waste is recycled or valorised energetically, EU accomplishing an average 69\% share (PlasticsEurope 2016), nevertheless in developing countries a significant percentage is still landfilled or sent to other environmental compartments, affecting all the ecosystems (Kadir et al. 2013). 


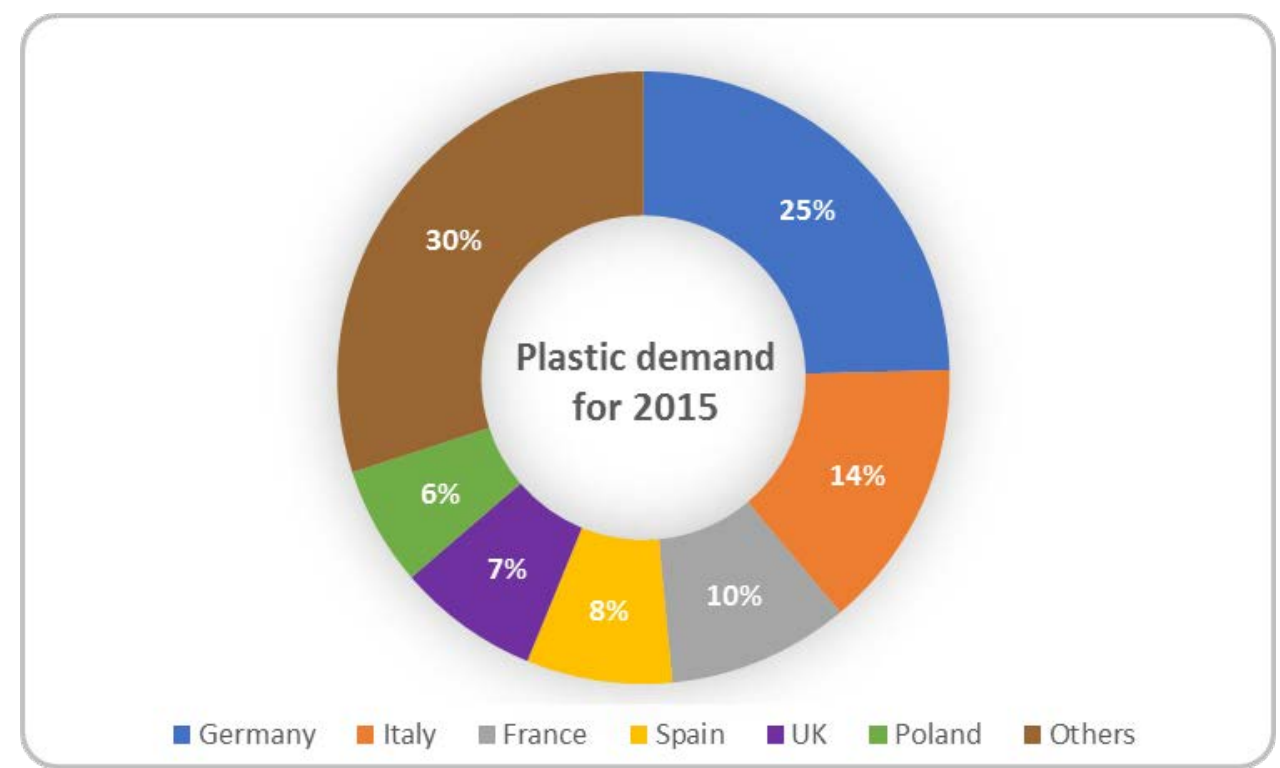

Figure 1: Plastic demand in Europe for 2015 (PlasticsEurope 2016)

An ambitious directive has set a "zero plastic to landfill" goal to be reached by 2025, reducing the landfill trend-line by 60 million tonnes, saving an equivalent amount of 750 million barrels of oil (PlasticsEurope 2016; Brems, Baeyens, and Dewil 2012). Marine pollution has recently been emphasised as one of the issues to account for in the Sustainable Development Goals in an attempt to secure "blue wealth". This is an imperious topic as these systems are being increasingly explored and marine policies are required, as well as planetary cooperation regarding a healthy ocean, that can continue to provide resources for a stable economy and general sustainability of the planet (Visbeck et al. 2014).

Nowadays, besides the issues regarding plastic safe disposal, a concerning matter is the occurrence of microplastics in the environment as reported in recent reviews of current trends and future perspectives in this matter (Barboza and Gimenez 2015; Shim and Thomposon 2015). Microplastics are small particles of plastic (diameter $\leq 5 \mathrm{~mm}$ ) which can have two different sources: primary, when they enter directly to the environment, mostly as raw material from the plastic industry or as micro-components present in cosmetic or hygiene products like toothpastes, shampoos, soaps or lotions (Cole et al. 2011); secondary, when they appear indirectly in the environment from the degradation of bigger plastic fractions due to the action of climatic conditions or physical elements, like sunlight or erosion (Andrady 2011). Whether they are directly flushed down sanitary facilities, or their parent compounds are unduly thrown to water courses being exposed to aggressive conditions that disintegrate them, microplastics become easily available to the existing wildlife, possibly causing death or harm through ingestion, entanglement, chemical pollution interactions or trophic transfer (Li, Tse, and Fok 2016; Ivar do Sul and Costa 2014; Wright, Thompson, and Galloway 2013; Sigler 2014). This effect is in an early stage of investigation but some authors have already characterized fractions of microplastics in sediments sampled in natural reserves exposing their polymer types and also their additive contents (Fries et al. 2013; Lozoya et al. 2016). Other works report possible scale-up effects reaching man through seafood (Van Cauwenberghe and Janssen 2014) and fishes (Rochman et al. 2015) intake. If fauna and flora threatening was not a sufficient reason to draw the attention of the legal authorities, this finding should set an alarm due to a possible impending catastrophe, which could reach several communities and generations around the world. 
Two possible approaches to reduce microplastics formation are: to promote and implement the production and utilization of biodegradable plastics or to intervene in the waste management systems so that they can take in such noxious residues (Pettipas, Bernier, and Walker 2016). The first case is still seen as an ambiguous option as, besides starch and vegetable oils, some of the ecological formulations also include synthetic polymers (although in smaller portions, when compared to traditional plastic products), accounting for a reduced degradation time, but not to a total biodegradability (O'Brine and Thompson 2010; Müller, Townsend, and Matschullat 2012). More research is needed to achieve better options, and legislation that preconize these sustainable alternatives should be enforced so that they can gradually replace the existing ones. Meanwhile, waste management systems are being assessed under a dual perspective, reducing plastic residues at the source, i.e. before entering the environment, or as a clean-up strategy (Rochman 2016).

This work will focus on the second procedure, highlighting plastics as a valuable feedstock in the view of the waste to energy (WtE) methodologies, constituting a very promising means of creating highly claimed assets.

\section{Methodology}

A dedicated search for literature was conducted making use of the online resources available for the academic community of the Faculty of Engineering of the University of Porto, namely scientific databases like Web of Science, Scopus and Inspec, along with specific individual editorial webpages, in some cases. Foremost techniques were used in order to limit the existing literature and to manage references, further case-by-case assessment of the results being performed (Öchsner 2013) in an attempt to resume what has already been done and to establish a link between that and the less-explored possibilities that could be taken into account in the future.

\section{Discussion}

In this chapter, a brief description of the thermal conversion of residues will be steered, contextualizing the waste-to-energy process as well as emphasizing its major contributions to a more sustainable waste management system. Also, a possible option to lessen microplastics as environmental debris will be suggested, as a combination of the reviewed literature and the knowledge of the thermochemical conversion methods.

\subsection{Waste-to-energy}

Among other options such as recycling and composting, energetic valorization is one of the possible mechanisms through which waste streams may be treated. Thermochemical processes enable the recovery of energy from residues, consisting in a waste-to-energy (WtE) technique (Bosmans et al. 2013). The most common thermochemical methods are described in Table 1.

Pyrolysis consists in the thermal degradation of feedstocks at relatively low temperatures, affording three different product fractions: liquid, gas and solid. Besides the necessary pretreatment this method involves, the obtained fractions require a final treatment to the achievement of energetically usable oils, and the simultaneous breakdown of the organic contents. Waste pyrolysis can afford several hundred different compounds, most of them considered useless or, worse than that contaminants, which can entail additional cleaning procedures (Bosmans et al. 2013). Incineration is the waste degradation through oxidation of the combustible species, giving rise to energy in the form of heat. This is accomplished in different stages, which can be controlled in order to reduce pollutant emissions such as furans and dioxins. Besides these compounds, fly and bottom ashes, dust and other residues are 
produced, gas cleaning equipment being mandatory, according to specific legislation (Bosmans et al. 2013).

Gasification is a thermochemical conversion scheme that converts carbonaceous materials into a synthetic gas (syngas), composed of carbon monoxide, hydrogen, methane, carbon dioxide and nitrogen (Balat et al. 2009; Basu 2010). Sometimes using catalysts such as quartzite sand or $\mathrm{Ni}$-based compounds promotes $\mathrm{H}_{2}$ formation, while reducing methane (Ruoppolo et al. 2012) or even endorses smaller activation energies (Chin et al. 2014), enabling faster reactions and easier conversions. Catalysts like $\mathrm{Ni}$-based, iron-based, calcined dolomites and magnesites, zeolites and olivine act in situ, advocating chemical reactions that alter syngas composition and heating value (Pinto et al. 2015).

\begin{tabular}{cccc}
\hline Process & Pyrolysis & Incineration & Gasification \\
\hline Temperature $\left({ }^{\circ} \mathrm{C}\right)$ & $380-530$ & $800-1300$ & $500-1800$ \\
Pressure $(\mathrm{MPa})$ & $0.1-0.5$ & $>0.1$ & $>0.1$ \\
Pre-treatment & Necessary & Useful & Necessary \\
Catalyst & Not necessary & Not necessary & Useful
\end{tabular}

Table 1: Summary comparison for the major thermochemical conversion processes, adapted from Basu (2010)

As seen in Table 1, gasification depicts higher temperatures allowing a wider range of materials to be encompassed, and assuring a cleaner technology once nearly all the subproducts or contaminants will be precluded. Thus, gasification promotes efficient results for several kinds of residues, reducing waste amounts with the benefit of producing important assets like heat, electricity, fuels and chemicals (Bosmans et al. 2013; Lupa et al. 2011; Brems, Baeyens, and Dewil 2012; Arafat, Jijakli, and Ahsan 2015). It occurs through a sequence of interdependent events from drying to pyrolysis, oxidation and reduction being described by a set of reactions inside the gasification chamber (Li, Zhang, and Bi 2010; Basu 2010), as shown in Figure 2.

Numerous authors report gasification appliance to different debris, e.g. biomass (Ahmad et al. 2016; Brito, Oliveira, and Rodrigues 2014; Fremaux et al. 2015; Kuo and Wu 2015; Ogi et al. 2013; Sansaniwal et al. 2017; Wang et al. 2015), municipal solid wastes (Arena 2012; Couto et al. 2015a; Couto et al. 2015b; Hu et al. 2015; Wang et al. 2012) and even mixtures of diverse feedstocks (Lahijani et al. 2013; Kawamoto and Lu 2016; Đurišić-Mladenović, Škrbić, and Zabaniotou 2016; Akkache et al. 2016; Ong et al. 2015; Pinto et al. 2014; Zaccariello and Mastellone 2015; Zhu et al. 2015). Although there are several types of gasifiers (Arena 2012), these may be generally classified in three main categories according to some technical and operational features, as defined in Table 2. The choice of each particular gasifier depends on multiple factors such as the syngas quality required and the size of the feedstock particles, each of them featuring also different operational conditions and restrictions (Guell, Sandquist, and Sorum 2013; Arena 2012). In the case of biomass and wastes, fluidized beds are the most commonly used gasifiers as they tolerate a wider particle size range, which is crucial for this type of residues (Bosmans et al. 2013; van der Drift, van Doorn, and Vermeulen 2001; Siedlecki, de Jong, and Verkooijen 2011). 


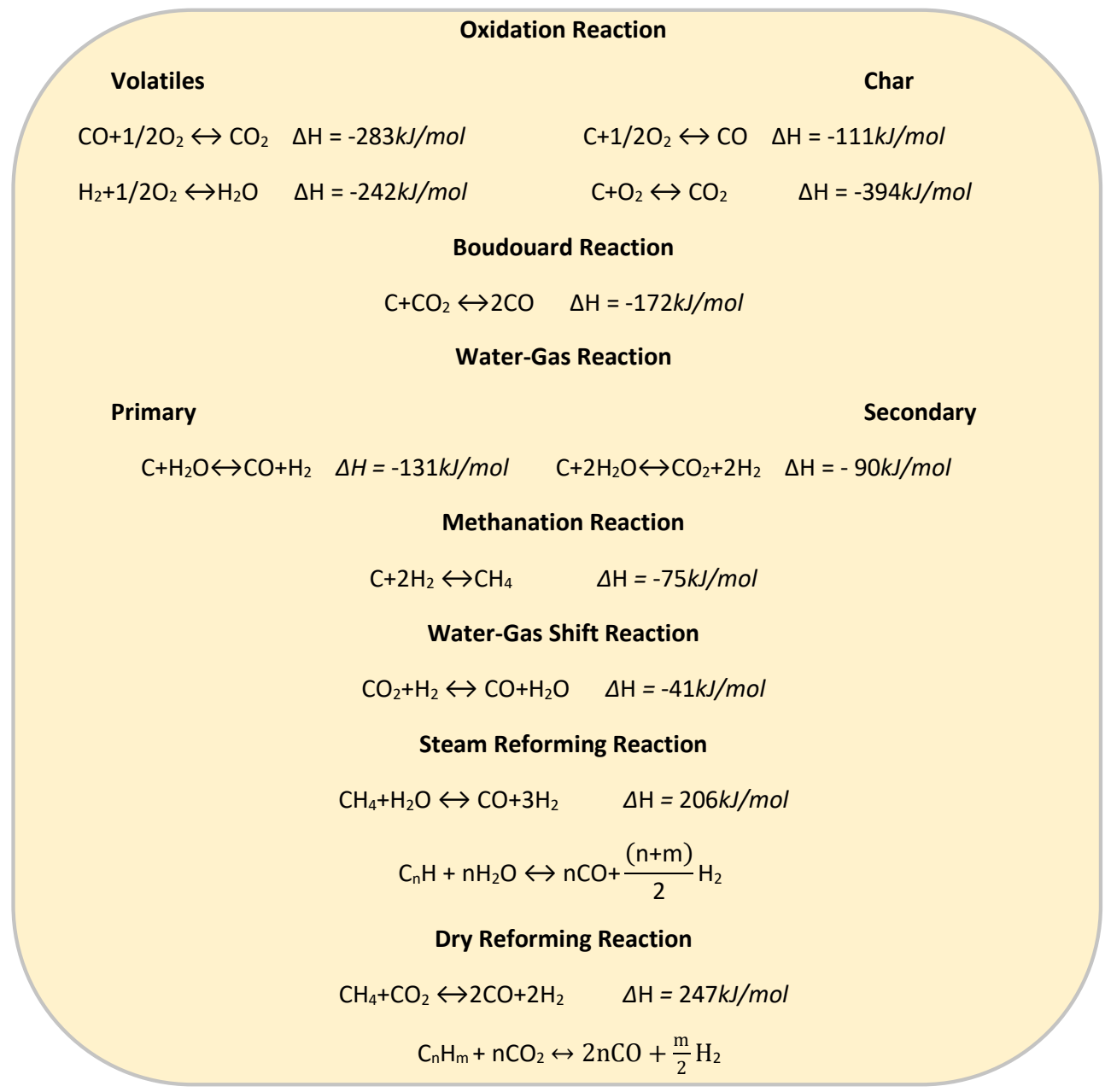

Figure 2: Brief description of gasification reactions in the chamber

\begin{tabular}{|c|c|c|c|c|c|}
\hline \multirow{2}{*}{$\begin{array}{c}\text { Gasifier } \\
\text { Type }\end{array}$} & \multirow{2}{*}{ Sub-type } & \multirow{2}{*}{ Temperature } & \multicolumn{2}{|c|}{ Flows } & \multirow{2}{*}{ Remarks } \\
\hline & & & Fuel & Oxidant & \\
\hline \multirow[b]{2}{*}{ Fixed Bed } & Updraft & \multirow[b]{2}{*}{$1000^{\circ} \mathrm{C}$} & downward & upward & Simple and robust, fuel size \\
\hline & Downdraft & & downward & downward & $\begin{array}{c}\text { and moisture content } \\
\text { restrictions }\end{array}$ \\
\hline \multirow{2}{*}{$\begin{array}{c}\text { Fluidized } \\
\text { Bed }\end{array}$} & Bubbling & \multirow{2}{*}{$800-850^{\circ} \mathrm{C}$} & upward & upward & Relatively low cost, ease of \\
\hline & Circulating & & upward & upward & $\begin{array}{c}\text { operation, good scale-up } \\
\text { potential }\end{array}$ \\
\hline $\begin{array}{c}\text { Entrained } \\
\text { Bed }\end{array}$ & --- & $1200-1500^{\circ} \mathrm{C}$ & downward & downward & $\begin{array}{l}\text { Higher costs, complex, fuel } \\
\text { size restrictions, suitable for } \\
\text { high capacities }\end{array}$ \\
\hline
\end{tabular}

Table 2: General classification for gasifiers according to bed type and reactor flows

\subsection{Microplastics gasification}

As plastics can be disposed of in diverse shapes, sizes and from a multitude of origins (including microplastics), the comprehensive character that gasification has to offer confirms this technique as a valuable conversion method for these residues, as reported by several authors (Al-Salem, Lettieri, and Baeyens 2009; Arena, Zaccariello, and Mastellone 2009; Aznar et al. 2006; Baloch et al. 2016; Kim et al. 2011), some even suggesting a possible replacement of fossil fuels (Straka and Bičáková 2014).

Apart from the assets achieved from plastics gasification, improved results were obtained for mixtures of plastics with other residues, due to their valuable energetic composition that 
contributes to ameliorated process outcomes (Ahmed, Nipattummakul, and Gupta 2011; Moghadam et al. 2014; Yang et al. 2015; Alvarez et al. 2014). This was shown by Ahmed, Nipattummakul, and Gupta (2011), who observed enhanced syngas yield and composition as well as higher energy contents and thermal efficiency for mixed samples of woodchips and polyethylene (PE). The comparison of the enriched syngas to the expected composition if linear behaviour occurred is represented in Figure 3 and it can be seen that the results of cogasification of the mixed samples are superior to the predictable values and also to the situations where the plastic residues or the biomass samples were gasified alone (0\% PE and $100 \% \mathrm{PE}$, respectively). The explanation may rely on the hydrogen donor capacity of the plastic residues, which stabilizes the radicals generated from biomass and also, on the contribution of biomass char to the adsorption of volatiles from polyethylene, exalting hydrogen production.

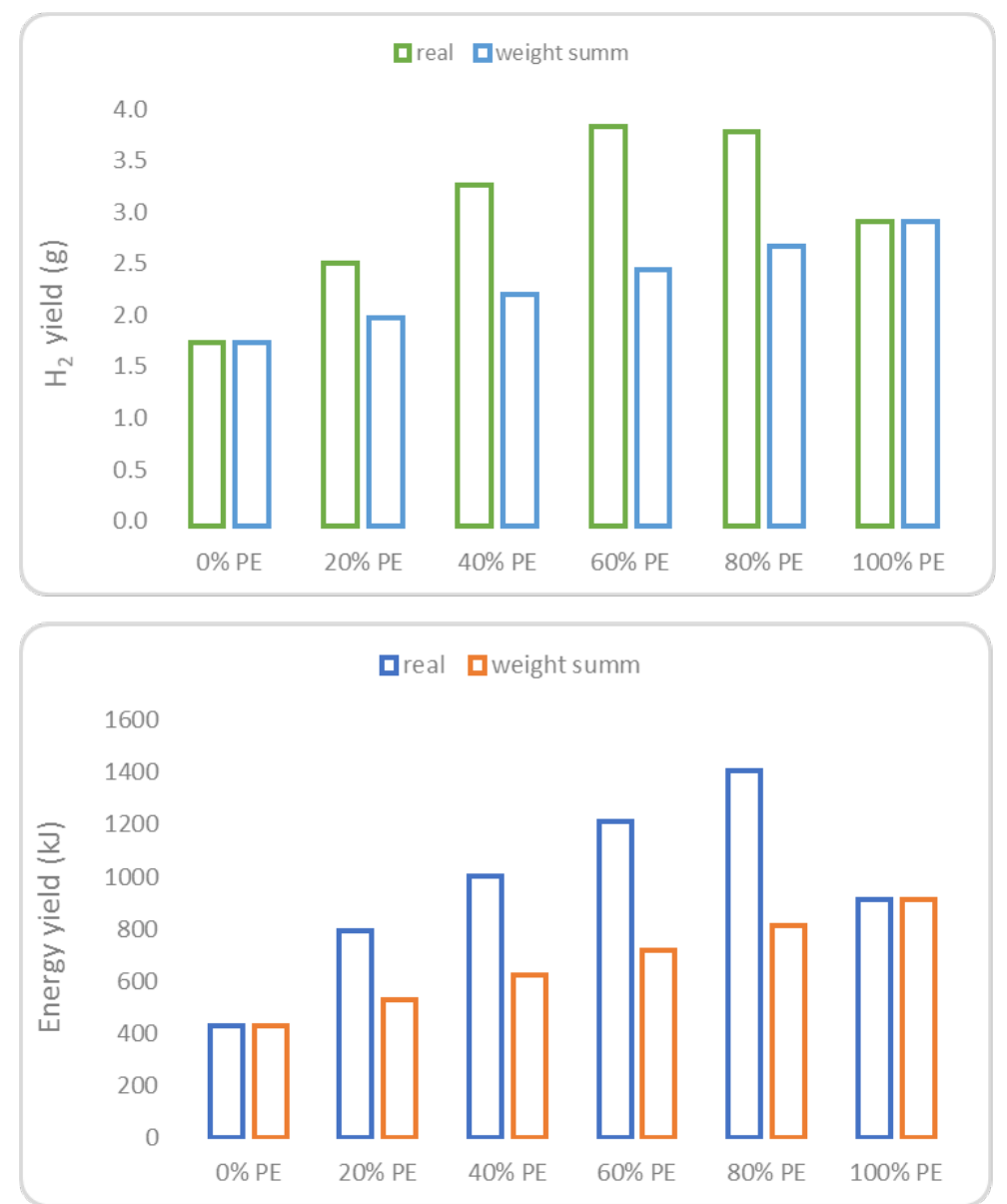

Figure 3: Synergistic effect of co-gasification of wood chips and polyethylene on hydrogen (top) and energy (bottom) yields, based on Ahmed, Nipattummakul, and Gupta (2011)

Moghadam et al. (2014) also reported upgraded syngas production and conversion rates when polyethylene ratio was raised in mixtures with palm kernel shell. This easier degradation was promoted by the higher volatile matter and lower ash contents of PE. Alvarez et al. (2014) investigated the addition of plastics to wood sawdust observing increased gaseous contents for higher plastic fractions as well. Yang et al. (2015) studied the gasification characteristics of rice straw (RS) with three different plastics (PE; polyethylene terephthalate - PET; polyvinyl chloride - PVC) and were able to find lower activation energies when compared to the weighted summation of the individual activation energies of the plastics and rice straw.

Figure 4 depicts a comparison of the activation energy obtained for the real samples to the projected for the linear addition of the weighted contribution of each fraction, synergistic 
effects between rice straw and all the plastic residues being registered, as can be seen from the lower activation energies achieved for real samples. This effect is more evident for PE than for PET or PVC, possibly due to its less bulky environment which enables faster reaction at high temperatures.

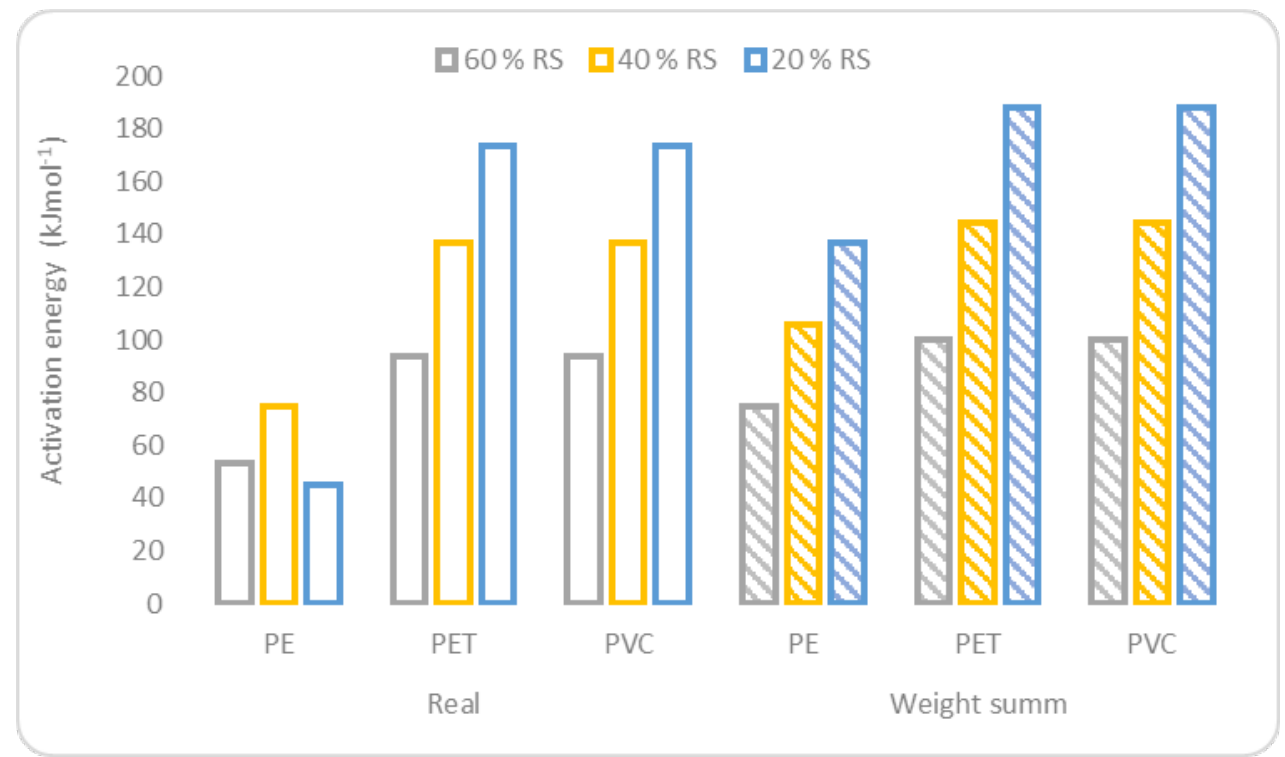

Figure 4: Synergistic effect of co-gasification of rice straw and different plastic residues, based on data from Yang et al. (2015)

Besides the benefits pointed hitherto, this synergetic effects boost gasification as a prominent technology especially in the case of plastic residues, taking advantage of their intrinsic properties to acquire upgraded results.

Referring to microplastics, to the best of the authors' knowledge there is only one published paper reviewing the microwave-induced plasma gasification (MIPG) of synthetic (and organic) waste polluting waterbodies (Panicker and Magid 2016). This work suggests the use of MIPG to clean rivers, lakes and even the ocean adapting the gasifier station to boats or platforms, so that waste is collected and conveyed to the reactor, the produced syngas being used to power the plant and the boat itself, among other commercial uses. Although this may seem complex or expensive to assemble and implement in a wide-range of countries and specific locations, gasification has indirectly shown to be adequate for microplastics as published in a manifold of papers that concern regular size-plastic residues, using pre-treatment steps such as shredding, pulverizing, sieving, grinding among others. All these actions reduce the particles size, which may be considered similar to using microplastics. In fact, reducing feedstock dimensions improves mass and heat transfer efficiencies due to larger surface areas and lower diffusion resistance coefficients, increasing reaction rates and fuel conversion (Hernández, Aranda-Almansa, and Bula 2010; Parthasarathy and Narayanan 2014). Figure 5 displays syngas composition and conversion rate for different particle sizes, a general decrease in both parameters being observed for bigger particles. 

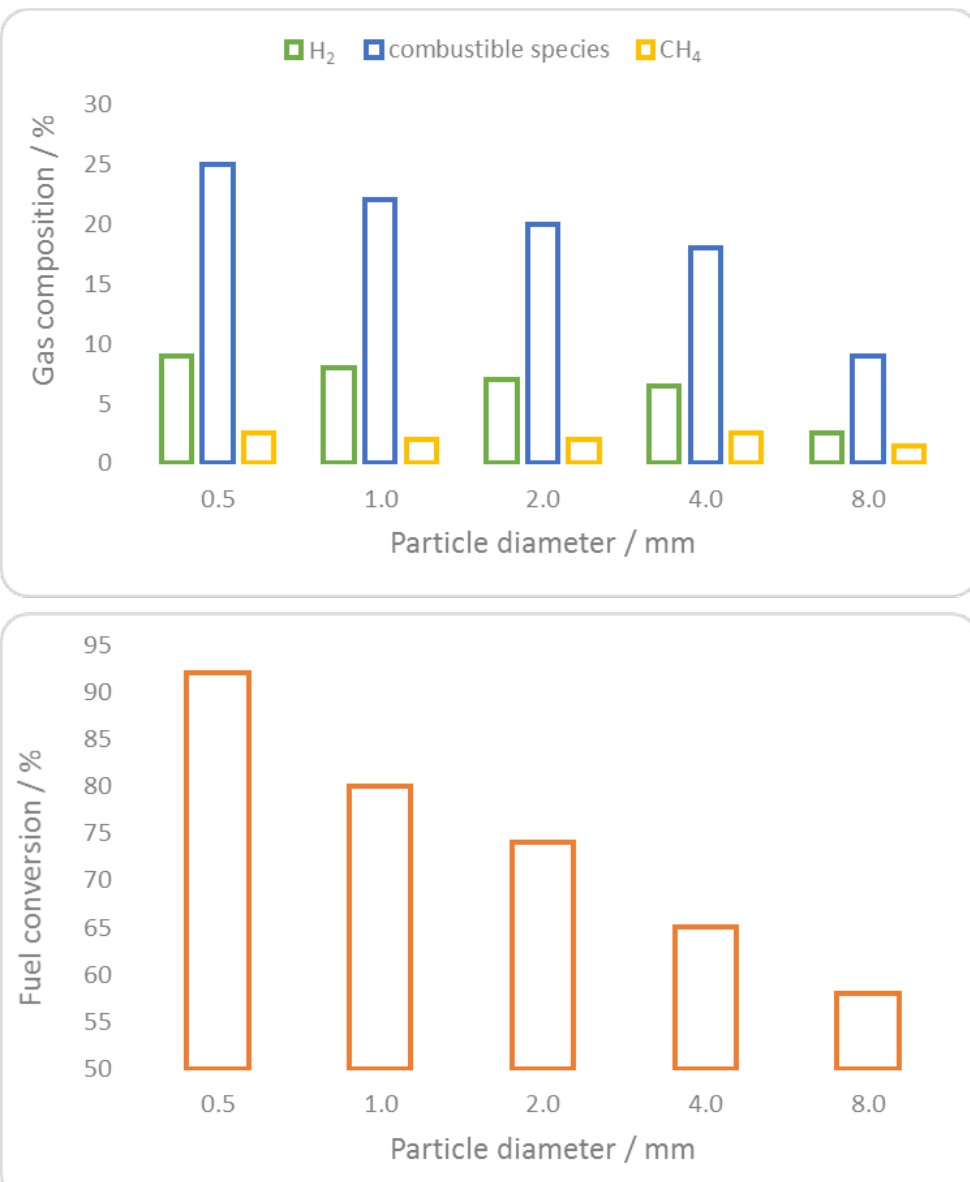

Figure 5: Effect of fuel particle size on syngas composition (top) and fuel conversion rate (bottom), based on Hernández, Aranda-Almansa, and Bula (2010)

Gasification reports of plastic residues that suffer a size reduction before the thermal conversion are widespread, some co-gasification examples clearly portraying the advantage of this step towards a more homogeneous feedstock (Chin et al. 2014; Lahijani et al. 2013; Moghadam et al. 2014).

\section{Conclusions}

This work aimed to potentiate gasification (and co-gasification) of (micro)plastics as an efficient and environmental-friendly method for treating this type of residues, aiding also to avoid their spread throughout the environmental compartments, in accordance to legislation and international recommendations. From the exposed, some findings could be highlighted helping to establish a logical sequence that can constitute a contribution to the aforementioned goal. WtE was presented as a dual-benefit method for turning environment more sustainable once it employs waste transforming it into energy and other assets, that become available for consumption without falling back on natural resources as fossil fuels do. From the major WtE techniques, gasification was shown to be the most suitable for plastic residues, namely fluidized beds have been reported as highly efficient reactors, due to their ability to comprise a vast range of feedstock dimensions. Several co-gasification reports on the interaction between plastic debris and other residues are published, revealing synergistic effects that promote enhanced results when compared to the single treatment of each of the fuels. Whereas gasification is strongly applied to regular plastic residues (bigger than microplastics) with excellent results, it demonstrates to be a favourable approach to the gasification of microplastics, as it commonly includes pre-treatment processes to reduce and 
homogenize feedstock dimensions, relevant evidences being stated in the case of cogasification. This is also sustained by the fact that smaller particles endorse more effective interactions inside the gasification chamber, once phenomena like heat and mass transfer are better accomplished, preconizing higher reaction rates and improved microplastics conversion. Thus, gasification of microplastics should be regarded as a possible contributor to achieve the so called "blue wealth", granting environmental and sustainable results in the reduction of marine, coastal or land based-polluted areas. Although numerous publications address gasification of plastic residues, more research is needed towards the implementation of this method in the specific case of microplastics in situ, as real conditions constitute a more tangible set of circumstances that can interfere with the global results. Therefore, the enforcement of technical measures that can embrace regional, national as well as international collaboration is highly required, so that the ocean's impact on environmental degradation can regress as quickly as possible.

\section{References}

Ahmad, A. A., N. A. Zawawi, F. H. Kasim, A. Inayat and A. Khasri. 2016. "Assessing the gasification performance of biomass: A review on biomass gasification process conditions, optimization and economic evaluation". Renewable \& Sustainable Energy Reviews 53:13331347. Accessed February 15, 2017. DOI: 10.1016/j.rser.2015.09.030.

Ahmed, I.I., N. Nipattummakul and A. K. Gupta. 2011. "Characteristics of syngas from cogasification of polyethylene and woodchips". Applied Energy 88 (1):165-174. Accessed March 3, 2016. DOI: 10.1016/j.apenergy.2010.07.007.

Akkache, Salah, Ana-Belén Hernández, Gabriel Teixeira, Franck Gelix, Nicolas Roche and Jean Henry Ferrasse. 2016. "Co-gasification of wastewater sludge and different feedstock: Feasibility study". Biomass and Bioenergy 89:201-209. Accessed February 15, 2017. DOI: 10.1016/j.biombioe.2016.03.003.

Al-Salem, S. M., P. Lettieri and J. Baeyens. 2009. "Recycling and recovery routes of plastic solid waste (PSW): A review". Waste Management 29 (10):2625-2643. Accessed February 29, 2016. DOI: 10.1016/j.wasman.2009.06.004.

Alvarez, J., S. Kumagai, C. F. Wu, T. Yoshioka, J. Bilbao, M. Olazar and P. T. Williams. 2014. "Hydrogen production from biomass and plastic mixtures by pyrolysis-gasification". International Journal of Hydrogen Energy 39 (21):10883-10891. Accessed January 25, 2016. DOI: 10.1016/j.ijhydene.2014.04.189.

Andrady, Anthony L. 2011. "Microplastics in the marine environment". Marine Pollution Bulletin 62 (8):1596-1605. Accessed March 9, 2017. DOI: 10.1016/j.marpolbul.2011.05.030.

Arafat, Hassan A., Kenan Jijakli and Amimul Ahsan. 2015. "Environmental performance and energy recovery potential of five processes for municipal solid waste treatment". Journal of Cleaner Production 105:233-240. Accessed May 10, 2016. DOI: 10.1016/j.jclepro.2013.11.071.

Arena, Umberto. 2012. "Process and technological aspects of municipal solid waste gasification. A review". Waste Management 32 (4):625-39. Accessed January 25, 2016. DOI: 10.1016/j.wasman.2011.09.025.

Arena, Umberto, Lucio Zaccariello and Maria Laura Mastellone. 2009. "Tar removal during the fluidized bed gasification of plastic waste". Waste Management 29 (2):783-791. Accessed April 8, 2016. DOI: 10.1016/j.wasman.2008.05.010.

Aznar, María P., Miguel A. Caballero, Jesús A. Sancho and E. Francés. 2006. "Plastic waste elimination by co-gasification with coal and biomass in fluidized bed with air in pilot plant". 
Fuel Processing Technology 87 (5):409-420. Accessed January 27, 2016. DOI: 10.1016/j.fuproc.2005.09.006.

Balat, Mustafa, Mehmet Balat, Elif Kırtay and Havva Balat. 2009. "Main routes for the thermoconversion of biomass into fuels and chemicals. Part 2: Gasification systems". Energy Conversion and Management 50 (12):3158-3168. Accessed January 25, 2016. DOI: 10.1016/j.enconman.2009.08.013.

Baloch, H. A., T. H. Yang, R. D. Li, S. Nizamuddin, X. P. Kai and A. W. Bhutto. 2016. "Parametric study of co-gasification of ternary blends of rice straw, polyethylene and polyvinylchloride". Clean Technologies and Environmental Policy 18 (4):1031-1042. Accessed February 17, 2017. DOI: 10.1007/s10098-016-1092-4.

Barboza, Luís Gabriel Antão and Barbara Carolina Garcia Gimenez. 2015. "Microplastics in the marine environment: Current trends and future perspectives". Marine Pollution Bulletin 97 (1):5-12. Accessed March 8, 2017. DOI: 10.1016/j.marpolbul.2015.06.008.

Basu, Prabir. 2010. Biomass gasification and pyrolysis: practical design and theory. Oxford, UK: Academic Press.

Bosmans, A., I. Vanderreydt, D. Geysen and L. Helsen. 2013. "The crucial role of Waste-toEnergy technologies in enhanced landfill mining: a technology review". Journal of Cleaner Production 55:10-23. Accessed January 25, 2016. DOI: 10.1016/j.jclepro.2012.05.032.

Brems, A., J. Baeyens and R. Dewil. 2012. "Recycling and recovery of post-consumer plastic solid waste in a European context". Thermal Science 16 (3):669-685. Accessed November 23, 2016. DOI: 10.2298/tsci120111121b.

Brito, Paulo S. D., Anabela S. Oliveira and Luiz F. Rodrigues. 2014. "Energy valorization of solid vines pruning by thermal gasification in a pilot plant". Waste and Biomass Valorization 5 (2):181-187. Accessed March 14, 2017. DOI: 10.1007/s12649-013-9246-7.

Chin, B. L. F., S. Yusup, A. Al Shoaibi, P. Kannan, C. Srinivasakannan and S. A. Sulaiman. 2014. "Comparative studies on catalytic and non-catalytic co-gasification of rubber seed shell and high density polyethylene mixtures". Journal of Cleaner Production 70:303-314. Accessed February 25, 2016. DOI: 10.1016/j.jclepro.2014.02.039.

Cole, Matthew, Pennie Lindeque, Claudia Halsband and Tamara S. Galloway. 2011. "Microplastics as contaminants in the marine environment: A review". Marine Pollution Bulletin 62 (12):2588-2597. Accessed March 9, 2017. DOI: 10.1016/j.marpolbul.2011.09.025.

Couto, Nuno Dinis, Valter Bruno Silva, Eliseu Monteiro and Abel Rouboa. 2015a. "Assessment of municipal solid wastes gasification in a semi-industrial gasifier using syngas quality indices". Energy 93, Part 1:864-873. Accessed January 25, 2016. DOI: 10.1016/j.energy.2015.09.064.

Couto, Nuno, Valter Silva, Eliseu Monteiro, Sandra Teixeira, Ricardo Chacartegui, K. Bouziane, P. S. D. Brito and Abel Rouboa. 2015b. "Numerical and experimental analysis of municipal solid wastes gasification process". Applied Thermal Engineering 78:185-195. Accessed January 25, 2016. DOI: 10.1016/j.applthermaleng.2014.12.036.

Đurišić-Mladenović, Nataša, Biljana D. Škrbić and Anastasia Zabaniotou. 2016. "Chemometric interpretation of different biomass gasification processes based on the syngas quality: Assessment of crude glycerol co-gasification with lignocellulosic biomass". Renewable and Sustainable Energy Reviews 59:649-661. Accessed February 15, 2017. DOI: 10.1016/j.rser.2016.01.002. 
Eerkes-Medrano, Dafne, Richard C. Thompson and David C. Aldridge. 2015. "Microplastics in freshwater systems: A review of the emerging threats, identification of knowledge gaps and prioritisation of research needs". Water Research 75:63-82. Accessed March 11, 2017. DOI: 10.1016/j.watres.2015.02.012.

Fremaux, Sylvain, Sayyed-Mohsen Beheshti, Hojat Ghassemi and Rasoul ShahsavanMarkadeh. 2015. "An experimental study on hydrogen-rich gas production via steam gasification of biomass in a research-scale fluidized bed". Energy Conversion and Management 91:427-432. Accessed March 14, 2017. DOI: 10.1016/j.enconman.2014.12.048.

Fries, E., J. H. Dekiff, J. Willmeyer, M. T. Nuelle, M. Ebert and D. Remy. 2013. "Identification of polymer types and additives in marine microplastic particles using pyrolysis-GC/MS and scanning electron microscopy". Environmental Science: Processes \& Impacts 15 (10):19491956. Accessed March 6, 2017. DOI: 10.1039/C3EM00214D.

Guell, Berta Matas, Judit Sandquist and Lars Sorum. 2013. "Gasification of biomass to second generation biofuels: a review". In Proceedings of the Asme 5th International Conference on Energy Sustainability 2011, Pts a-C, 1119-1129. Original edition, Journal of Energy Resources Technology, vol.135 (2013). Accessed March 14, 2017. DOI: 10.1115/ES201154140.

Hernández, Juan J., Guadalupe Aranda-Almansa and Antonio Bula. 2010. "Gasification of biomass wastes in an entrained flow gasifier: Effect of the particle size and the residence time". Fuel Processing Technology 91 (6):681-692. Accessed January 26, 2016. DOI: 10.1016/j.fuproc.2010.01.018.

Hu, Mian, Dabin Guo, Caifeng Ma, Zhiquan Hu, Beiping Zhang, Bo Xiao, Siyi Luo and Jingbo Wang. 2015. "Hydrogen-rich gas production by the gasification of wet MSW (municipal solid waste) coupled with carbon dioxide capture". Energy 90:857-863. Accessed March 17, 2016. DOI: 10.1016/j.energy.2015.07.122.

Ivar do Sul, Juliana A. and Monica F. Costa. 2014. "The present and future of microplastic pollution in the marine environment". Environmental Pollution 185:352-364. Accessed March 9, 2017. DOI: 10.1016/j.envpol.2013.10.036.

Kadir, Sharifah Aishah Syed Abd, Chun-Yang Yin, Muhamad Rosli Sulaiman, Xi Chen and Mohanad El-Harbawi. 2013. "Incineration of municipal solid waste in Malaysia: Salient issues, policies and waste-to-energy initiatives". Renewable and Sustainable Energy Reviews 24:181-186. Accessed March 14, 2017. DOI: 10.1016/j.rser.2013.03.041.

Kawamoto, K. and B. W. Lu. 2016. "Gasification and reforming of biomass and waste samples by means of a novel catalyst". Journal of Material Cycles and Waste Management 18 (4):646-654. Accessed February 15, 2017. DOI: 10.1007/s10163-016-0533-9.

Kim, Jin-Won, Tae-Young Mun, Jin-O Kim and Joo-Sik Kim. 2011. "Air gasification of mixed plastic wastes using a two-stage gasifier for the production of producer gas with low tar and a high caloric value". Fuel 90 (6):2266-2272. Accessed March 14, 2017. DOI: 10.1016/j.fuel.2011.02.021.

Kuo, P. C. and W. Wu. 2015. "Design, optimization and energetic efficiency of producing hydrogen-rich gas from biomass steam gasification". Energies 8 (1):94-110. Accessed February 23, 2017. DOI: 10.3390/en8010094.

Lahijani, P., Z. A. Zainal, A. R. Mohamed and M. Mohammadi. 2013. "Co-gasification of tire and biomass for enhancement of tire-char reactivity in $\mathrm{CO} 2$ gasification process". Bioresource Technology 138:124-130. Accessed January 25, 2016. DOI: 10.1016/j.biortech.2013.03.179. 
$\mathrm{Li}$, Kezhong, Rong Zhang and Jicheng Bi. 2010. "Experimental study on syngas production by co-gasification of coal and biomass in a fluidized bed". International Journal of Hydrogen Energy 35 (7):2722-2726. Accessed January 26, 2016. DOI: 10.1016/j.ijhydene.2009.04.046.

Li, W. C., H. F. Tse and L. Fok. 2016. "Plastic waste in the marine environment: A review of sources, occurrence and effects". Science of the Total Environment 566:333-349. Accessed March 8, 2017. DOI: 10.1016/j.scitotenv.2016.05.084.

Lozoya, J. P., F. T. de Mello, D. Carrizo, F. Weinstein, Y. Olivera, F. Cedres, M. Pereira and M. Fossati. 2016. "Plastics and microplastics on recreational beaches in Punta del Este (Uruguay): Unseen critical residents?". Environmental Pollution 218:931-941. Accessed March 6, 2017. DOI: 10.1016/j.envpol.2016.08.041.

Lupa, Christopher J., Lois J. Ricketts, Andy Sweetman and Ben M. J. Herbert. 2011. "The use of commercial and industrial waste in energy recovery systems - A UK preliminary study". Waste Management 31 (8):1759-1764. Accessed January 25, 2016. DOI: 10.1016/j.wasman.2011.04.002.

Moghadam, R. A., S. Yusup, Y. Uemura, B. L. F. Chin, H. L. Lam and A. Al Shoaibi. 2014. "Syngas production from palm kernel shell and polyethylene waste blend in fluidized bed catalytic steam co-gasification process". Energy 75:40-44. Accessed January 25, 2016. DOI: 10.1016/j.energy.2014.04.062.

Müller, Christin, Kathy Townsend and Jörg Matschullat. 2012. "Experimental degradation of polymer shopping bags (standard and degradable plastic, and biodegradable) in the gastrointestinal fluids of sea turtles". Science of the Total Environment 416:464-467. Accessed March 10, 2017. DOI: 10.1016/j.scitotenv.2011.10.069.

O'Brine, Tim and Richard C. Thompson. 2010. "Degradation of plastic carrier bags in the marine environment". Marine Pollution Bulletin 60 (12):2279-2283. Accessed March 10, 2017. DOI: 10.1016/j.marpolbul.2010.08.005.

Öchsner, Andreas. 2013. Introduction to Scientific Publishing: Backgrounds, Concepts, Strategies. Heidelberg: Springer.

Ogi, Tomoko, Masakazu Nakanishi, Yoshio Fukuda and Keigo Matsumoto. 2013. "Gasification of oil palm residues (empty fruit bunch) in an entrained-flow gasifier". Fuel 104:28-35. Accessed April 6, 2016. DOI: 10.1016/j.fuel.2010.08.028.

Ong, Z. H., Y. P. Cheng, T. Maneerung, Z. Y. Yao, Y. W. Tong, C. H. Wang and Y. J. Dai. 2015. "Co-gasification of woody biomass and sewage sludge in a fixed-bed downdraft gasifier". Aiche Journal 61 (8):2508-2521. Accessed January 25, 2016. DOI: 10.1002/aic.14836.

Panicker, P. K. and A. Magid. 2016. "Microwave plasma gasification for the restoration of urban rivers and lakes, and the elimination of oceanic garbage patches". Proceedings of the Asme 10th International Conference on Energy Sustainability, 2016, Vol 1. Accessed March 6, 2017. DOI: 10.1115/ES2016-59632.

Parthasarathy, P. and K. S. Narayanan. 2014. "Hydrogen production from steam gasification of biomass: Influence of process parameters on hydrogen yield - A review". Renewable Energy 66:570-579. Accessed March 15, 2016. DOI: 10.1016/j.renene.2013.12.025.

Pettipas, Shauna, Meagan Bernier and Tony R. Walker. 2016. "A Canadian policy framework to mitigate plastic marine pollution". Marine Policy 68:117-122. Accessed March 7, 2017. DOI: 10.1016/j.marpol.2016.02.025.

Pinto, F., R. N. Andre, C. Carolino and M. Miranda. 2014. "Hot treatment and upgrading of syngas obtained by co-gasification of coal and wastes". Fuel Processing Technology 126:1929. Accessed January 25, 2016. DOI: 10.1016/j.fuproc.2014.04.016. 
Pinto, Filomena, Rui Neto André, Carlos Carolino, Miguel Miranda, Pedro Abelha, Daniel Direito, Jesper Dohrup, Hanne Risbjerg Sørensen and Francisco Girio. 2015. "Effects of experimental conditions and of addition of natural minerals on syngas production from lignin by oxy-gasification: Comparison of bench- and pilot scale gasification". Fuel 140:6272. Accessed April 6, 2016. DOI: 10.1016/j.fuel.2014.09.045.

PlasticsEurope. 2016. Plastics-the Facts 2016. An Analysis of European Plastics Production, Demand and Waste Data. Association of Plastics Manufacturers Brussels.

Rochman, C. M. 2016. "Strategies for reducing ocean plastic debris should be diverse and guided by science". Environmental Research Letters 11 (4):041001. Accessed March 6, 2017. DOI: 10.1088/1748-9326/11/4/041001.

Rochman, Chelsea M., Akbar Tahir, Susan L. Williams, Dolores V. Baxa, Rosalyn Lam, Jeffrey T. Miller, Foo-Ching Teh, Shinta Werorilangi and Swee J. Teh. 2015. "Anthropogenic debris in seafood: Plastic debris and fibers from textiles in fish and bivalves sold for human consumption". Scientific Reports 5:14340. Accessed March 14, 2017. DOI: 10.1038/srep14340.

Ruoppolo, G., P. Ammendola, R. Chirone and F. Miccio. 2012. "H2-rich syngas production by fluidized bed gasification of biomass and plastic fuel". Waste Management 32 (4):724-732. Accessed November 8, 2016. DOI: 10.1016/j.wasman.2011.12.004.

Sansaniwal, S. K., K. Pal, M. A. Rosen and S. K. Tyagi. 2017. "Recent advances in the development of biomass gasification technology: A comprehensive review". Renewable and Sustainable Energy Reviews 72:363-384. Accessed March 14, 2017. DOI: 10.1016/j.rser.2017.01.038.

Shim, W. J. and R. C. Thomposon. 2015. "Microplastics in the ocean". Archives of Environmental Contamination and Toxicology 69 (3):265-268. Accessed March 6, 2017. DOI: 10.1007/s00244-015-0216-x.

Siedlecki, Marcin, Wiebren de Jong and Adrian H. M. Verkooijen. 2011. "Fluidized bed gasification as a mature and reliable technology for the production of bio-syngas and applied in the production of liquid transportation fuels - A review". Energies 4 (3):389-434. Accessed January 25, 2016. DOI: 10.3390/en4030389.

Sigler, Michelle. 2014. "The effects of plastic pollution on aquatic wildlife: current situations and future solutions". Water, Air, \& Soil Pollution 225 (11):2184. Accessed March 14, 2017. DOI: 10.1007/s11270-014-2184-6.

Straka, Pavel and Olga Bičáková. 2014. "Hydrogen-rich gas as a product of two-stage cogasification of lignite/waste plastics mixtures". International Journal of Hydrogen Energy 39 (21):10987-10995. Accessed February 16, 2017. DOI: 10.1016/j.ijhydene.2014.05.054.

Van Cauwenberghe, Lisbeth and Colin R. Janssen. 2014. "Microplastics in bivalves cultured for human consumption". Environmental Pollution 193:65-70. Accessed March 11, 2017. DOI: 10.1016/j.envpol.2014.06.010.

van der Drift, A., J. van Doorn and J. W. Vermeulen. 2001. "Ten residual biomass fuels for circulating fluidized-bed gasification". Biomass and Bioenergy 20 (1):45-56. Accessed April 11, 2016. DOI: 10.1016/S0961-9534(00)00045-3.

Visbeck, M., U. Kronfeld-Goharani, B. Neumann, W. Rickels, J. Schmidt, E. van Doom, N. MatzLuck, K. Ott and M. F. Quaas. 2014. "Securing blue wealth: The need for a special sustainable development goal for the ocean and coasts". Marine Policy 48:184-191. Accessed March 14, 2017. DOI: 10.1016/j.marpol.2014.03.005. 
Wang, Jingbo, Gong Cheng, Yanli You, Bo Xiao, Shiming Liu, Piwen He, Dabin Guo, Xianjun Guo and Guijuan Zhang. 2012. "Hydrogen-rich gas production by steam gasification of municipal solid waste (MSW) using NiO supported on modified dolomite". International Journal of Hydrogen Energy 37 (8):6503-6510. Accessed March 14, 2017. DOI: 10.1016/j.ijhydene.2012.01.070.

Wang, Zhiqi, Tao He, Jianguang Qin, Jingli Wu, Jianqing Li, Zhongyue Zi, Guangbo Liu, Jinhu Wu and Li Sun. 2015. "Gasification of biomass with oxygen-enriched air in a pilot scale twostage gasifier". Fuel 150:386-393. Accessed June 1, 2016. DOI: 10.1016/j.fuel.2015.02.056.

Wright, Stephanie L., Richard C. Thompson and Tamara S. Galloway. 2013. "The physical impacts of microplastics on marine organisms: A review". Environmental Pollution 178:483492. Accessed March 9, 2017. DOI: 10.1016/j.envpol.2013.02.031.

Yang, T. H., K. M. Hu, R. D. Li, Y. Sun and X. P. Kai. 2015. "Cogasification of typical plastics and rice straw with carbon dioxide". Environmental Progress \& Sustainable Energy 34 (3):789794. Accessed January 25, 2016. DOI: 10.1002/ep.12041.

Zaccariello, L. and M. L. Mastellone. 2015. "Fluidized-bed gasification of plastic waste, wood, and their blends with coal". Energies 8 (8):8052-8068. Accessed January 25, 2016. DOI: 10.3390/en8088052.

Zhu, Y. J., P. Piotrowska, P. J. van Eyk, D. Bostrom, C. W. Kwong, D. B. Wang, A. J. Cole, R. de Nys, F. G. Gentili and P. J. Ashman. 2015. "Cogasification of Australian brown coal with algae in a fluidized bed reactor." Energy \& Fuels 29 (3):1686-1700. Accessed January 25, 2016. DOI: 10.1021/ef502422t.

\section{Aknowledgements}

Ana Ramos thanks the Portuguese Foundation for Science and Technology for her PhD grant [grant number SFRH/BD/110787/2015]. 